\title{
Natural Fibre Reinforced Polymer Composites: A Review on Dynamic Mechanical Properties
}

\author{
MK Gupta ${ }^{1 *}$ and Ajaya Bharti ${ }^{2}$ \\ ${ }^{1}$ Department of Mechanical Engineering, Motilal Nehru National Institute of Technology, Allahabad, India \\ ${ }^{2}$ Department of Applied Mechanics, Motilal Nehru National Institute of Technology Allahabad, India
}

Submission: October 03, 2017; Published: November 16, 2017

*Corresponding author: MK Gupta, Department of Mechanical Engineering, Motilal Nehru National Institute of Technology Allahabad, Allahabad-211004, India, Email: mnnit.manoj@gmail.com; mkgupta@mnnit.ac.in

\begin{abstract}
Natural Fibre Reinforced Polymer Composites (NFRPCs) reflect excellent and comparable mechanical and dynamic mechanical properties than steel, aluminum and other composite materials. Dynamic Mechanical Analysis (DMA) has been one of the widely used technique among thermal analysis techniques such as Thermo Gravimetric Analysis (TGA), Differential Scanning Calorimetry (DSC) and Thermal Mechanical Analysis (TMA). This technique is useful to measure dynamic mechanical properties such as storage modulus $\left(E^{\prime}\right)$, loss modulus $\left(E^{\prime \prime}\right)$, damping $(\operatorname{Tan} \delta)$ and glass transition temperature $\left(T_{g}\right)$ as a function of temperature of NFRPCs and other materials. Several studies had been carried out on dynamic mechanical properties of NFRPCs. This fact motivated to summarize these studies, therefore a review on dynamic mechanical properties of NFRPCs is presented in this communication.
\end{abstract}

\section{Introduction}

To overcome the environmental imbalance, interest of researchers and scientist has been grown in proper consumption of natural fibres opposite to synthetic fibres due to their advantages such as low cost and density, huge availability, environmental friendliness, renewability, biodegradability, high specific strength, high stiffness and easy processing [1-7]. Nevertheless, these fibres also face some demerits such as higher moisture absorption, poor thermal stability, lower interfacial bonding and lower impact strength [8-14]. NFRPCs are being used in various applications such as packaging, building and construction, electrical and electronics, house wares, marine, aerospace and so far [15-17].

Performance of NFRPCs is required to investigate not only under static stress but also under cyclic stress prior to their applications as above mentioned using some more advanced analysis; DMA is one of them. DMA is useful in analysis of dynamic mechanical properties of the NFRPCs as a function of frequency, temperature, time, stress, and atmosphere. Dynamic mechanical properties of NFRPCs mainly depend upon weight/volume percentages, shape and size, and stacking sequences of fibres. In addition to this, hybridization of fibres also influences the dynamic mechanical properties. Moreover, dynamic mechanical properties of NFRPCs are also affected by chemical treatments of fibres and incorporation of nano fillers.

Recently, dynamic mechanical analysis of NFRPCs has been increasingly increased, and several researchers had reported studies on the same. The present study shows the gentle effort to compile literatures available on dynamic mechanical analysis of NFRPCs.

\section{Dynamic mechanical analysis}

DMA technique is useful in characterising the NFRPCs in terms of morphology, viscoelastic behaviour, cross linking density, dynamic fragility, storage modulus, loss modulus, glass transition temperature, stress relaxation modulus and effective constant of reinforcement. In addition, DMA is also useful to characterize an important parameter damping as a function of frequency, temperature, time, stress, atmosphere or a combination of these parameters. Moreover, DMA is also very useful in civil infrastructure systems because dynamic loading conditions are frequently stumbling due to sound, earthquakes, winds, ocean waves and live loads. Vibration damping parameters shows prime importance for structural applications in order to enhance the reliability, performance, buildings comfort and in the alleviation of bridges hazards [18].

DMA characterize the mechanical responses of a material by monitoring dynamic property changes as a function of frequency, temperature or time. In DMA, an oscillating force is applied on sample and the sinusoidal stress and strain curves are recorded as a function of time. A typical such response is shown in Figure 1.

The modulus from DMA is not exactly same as the Young's modulus from stress-strain diagram. The slope of initial linear region of stress-strain diagram is Young's modulus but in DMA, 
the complex modulus is calculated from materials response to sinusoidal loading. The complex modulus is ratio of stress and strain of material under test. The magnitude of complex modulus can be written as:

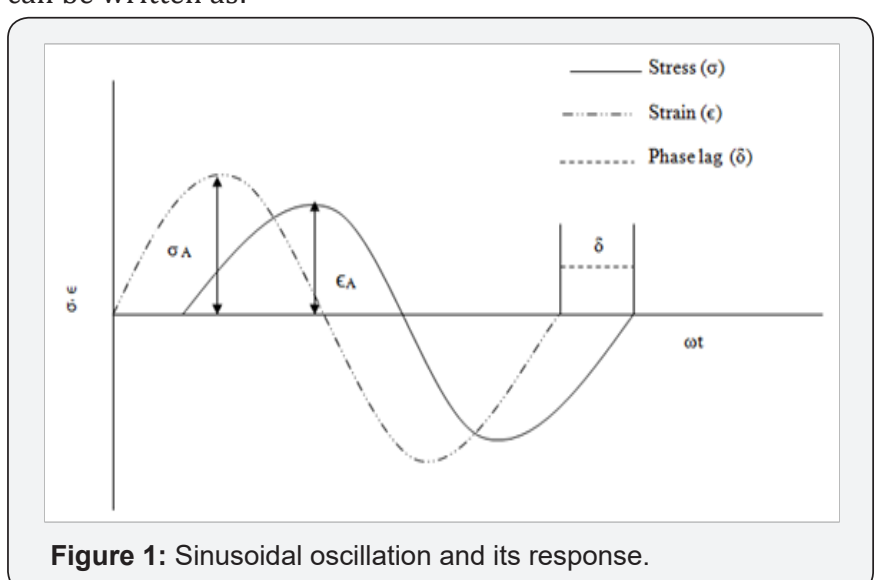

Complex modulus $(E)=\frac{\sigma}{\epsilon}$ (1)

Further, $E=E^{\prime}+i \quad E^{\prime \prime}(2)$

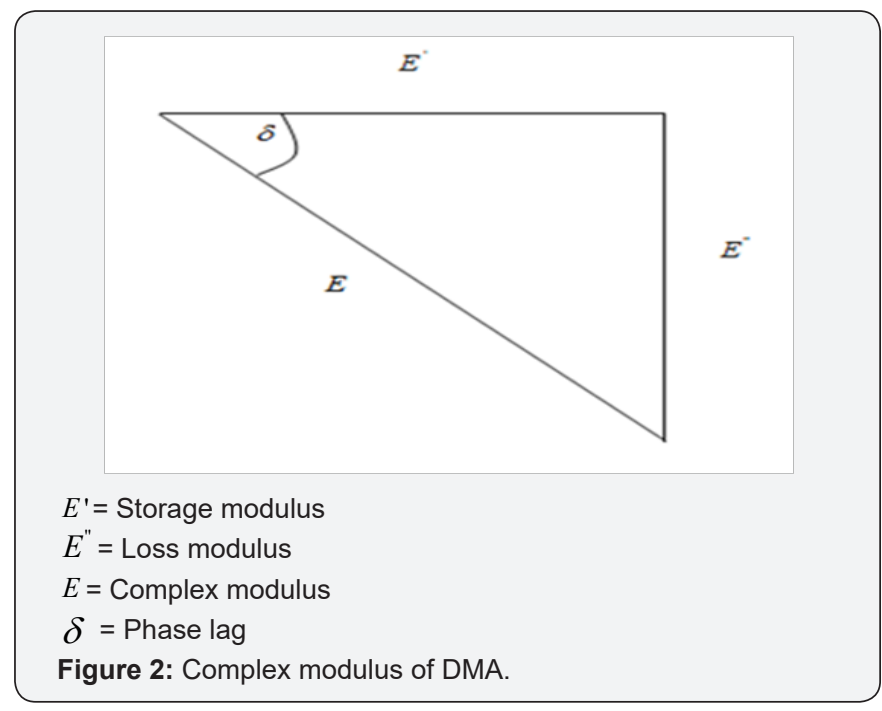

The real part of complex modulus $E^{\prime}$ is called storage modulus and imaginary part $E^{\prime \prime}$ is named loss modulus. It can be also obtained from the Figure 2. The following dynamic mechanical properties of materials can be obtained using DMA;

\section{Storage modulus}

It is a real part of complex modulus; defined as amount of the maximum energy stored by material during one cycle of oscillation [19-20]. It also gives an estimate of temperaturedependant stiffness behaviour and load-bearing capability of the polymer composites.

$$
\text { Storage modulus } E^{\prime}=E \quad \operatorname{Cos} \delta
$$

\section{Loss modulus}

The imaginary part of complex modulus is named as loss modulus; defined as amount of energy dissipated in form of heat by materials during one cycle of sinusoidal load $[19,20]$. It represents the viscous response of the polymer composites. The peak of loss modulus curve for polymer composites is known as dynamic glass transition temperature.

Loss modulus $E^{\prime}=E \operatorname{Sin} \delta$

\section{Damping}

The damping property of the polymer materials is the ratio of loss modulus and storage modulus. It is related to degree of molecular mobility in polymer composites $[19,20]$. The higher value of $\operatorname{Tan} \delta$ is characterized by high non-elastic behaviour while the low value of $\operatorname{Tan} \delta$ exhibit a high elastic behaviour of the material.

$$
\operatorname{Tan} \delta=\frac{E^{\prime \prime}}{E^{\prime}}
$$

\section{Glass transition temperature}

The glass transition temperature is the temperature range where state of polymer composites changes from a glassy (hard, rigid) to rubbery (flexible, yielding). The higher value of $T_{g}$ shows the higher thermal stability of polymer composites. Polymer composite loses its properties above $T_{g}$ which results into breaking of cross linking between molecules as gradually increase of further temperature. The glass transition temperature can be obtained from:

(i) Peak of tan delta curve.

(ii) Peak of loss modulus curve.

(iii) Storage modulus curve.

\section{Dynamic mechanical analysis of NFRPCs}

Dynamic mechanical analysis has become a far used technique to determine the interfacial characteristics of NFRPCs. Several researchers had reported studies on dynamic mechanical analysis of NFRPCs. Dynamic mechanical analysis of banana fibre reinforced polyester composites was studied by Pothan \& Oommen [21]; reported that the composite with 40 vol.\% fibre content had the maximum value of storage modulus, and lower value of loss modulus and damping parameters. In case of short sisal fibres reinforced polystyrene composites, storage modulus decreased upon increasing the temperature and the glass transition temperature of composite shifted towards lower temperature as compared to neat polystyrene [22]. Gupta \& Srivastava [23] presented study on dynamic mechanical properties of unidirectional jute fibre [23] and sisal fibres [24] reinforced epoxy composite. The viscoelastic behavior of jute fibre reinforced high density polyethylene was studied by Mohanty et al. [25]. It was observed that the storage modulus was found to increase with increase in fibre content up to $30 \%$. Shinoj et al. [26] investigated the dynamic mechanical properties of oil palm fibre linear low density polyethylene biocomposite in terms of storage modulus, loss modulus and damping parameter. The results suggested that the storage and loss modulus 
increased with increase in fibres content whereas the values of Tan $\delta$ peak decreased.

Several studies were made to investigate the effect of hybridization on dynamic mechanical properties of NFRPCs. Gupta \& Srivastava [27] investigated the dynamic mechanical properties of hybrid jute/sisal fibre reinforced epoxy composite in terms of storage modulus, loss modulus and damping, and found that each hybrid composite had a better dynamic mechanical performance than pure jute and sisal composite, which shows a positive effect of hybridization. The dynamic mechanical analysis of hybrid banana/sisal fibre reinforced polyester composites was carried out by Idicula et al. [28]. The composite with 40 vol.\% fibre content had the maximum storage modulus and peak width of $\operatorname{Tan} \delta$ but minimum height of damping. In case of DMA of hybrid composites, high strength glass fibres were frequently added with various natural fibres: sisal [29-31], ramie [32], bamboo [33], curaua [34-35], banana [36], pine apple leaf [37] and oil palm [38]. It was observed that dynamic mechanical properties of natural fibres were improved due to incorporation of glass fibres. The reason behind this fact may be due to a strong restriction imposed by the glass fibre to the polymer matrix, which allows a better stress transfer and hence improved dynamic mechanical properties.

Several studies were also made to investigate effect of surface modification of fibres by chemical treatment in order to increase adhesion between fibres and matrix, and thereby improvement in dynamic mechanical properties of NFRPCs. Shanmugam \& Thiruchitrambalam [39] proposed studies on effect of alkali treatment on dynamic mechanical properties of hybrid palmyra palm leak stalk/jute fibre reinforced polyester composite. It was reported that alkali treatment of fibres had improved dynamic mechanical properties. Influence of concentrations of alkali treatment on dynamic mechanical properties of hemp/polyester composite was reported by Gupta \& Gond [40]. The results suggested that the alkali treated hemp composites had a better storage modulus and glass transition temperature than untreated composites. The dynamic mechanical properties of vinylesterresin-matrix composites reinforced with alkali treated jute fibres were found to improved [41].

\section{Conclusion}

In this study, several studies on dynamic mechanical properties of NFRPCs have been presented, and main points are concluded as follows:

1. DMA is very useful technique to measure phase transitions of NFRPCs under influence of wide range of frequencies and temperature.

2. DMA is very helpful to accurately measure the storage modulus, loss modulus, damping and glass transition temperature of NFRPCs.
3. Dynamic mechanical properties were greatly influenced by fibre's contents, shape and size, and stacking sequences.

4. Variations in frequencies, chemical treatment of fibres and hybridization also affected the dynamic mechanical properties of NFRPCs.

\section{References}

1. Sahari J, Sapuan SM, Zainudin ES, Maleque MA (2013) Mechanical and thermal properties of environmentally friendly composites derived from sugar palm tree. Mater Des 52: 285-289.

2. Gupta MK, Srivastava RK (2016) Mechanical properties of hybrid fibres-reinforced polymer composite: A Review. Polym Plast Technol Eng 55(6): 626-642.

3. Gupta MK, Srivastava RK (2016) Mechanical, thermal and water absorption properties of hybrid sisal/jute fibre reinforced polymer composite. Indian J Eng Mater Sci 23(4): 231-238.

4. Parul Sahu, Gupta MK (2017) Sisal (Agave Sisalana) Fibre and its Polymer Based Composites: A Review on current developments. J Reinf Plast Compos.

5. Gupta MK, Srivastava RK, Sushil Kumar, Suresh Gupta, Binayak Nahak (2015) Mechanical and water absorption properties of hybrid sisal/ glass fibre reinforced epoxy composite. American J Polym Sci Eng 3(2): 208-219.

6. Gupta MK, Srivastava RK (2015) Effect of sisal fibre loading on wear and friction properties of jute fibre reinforced epoxy composite. American J Polym Sci Eng 3(2): 198-207.

7. Gupta MK, Srivastava RK (2016) A review on characterization of hybrid fibre reinforced polymer composite. American J Polym Sci Eng 4(1): $1-7$.

8. Gupta MK, Srivastava RK, Himanshu Bisaria (2015) Potential of jute fibre reinforced polymer composites: A review. I J Fib Text Res 5(3): 30-38.

9. Gupta MK, Srivastava RK (2015) Effect of sisal fibre loading on mechanical properties of jute fibre reinforced epoxy composite. Int J Adv Mech Aero Eng 2: 149-153.

10. Gupta MK, Srivastava RK (2015) Thermal and moisture absorption property of hybrid sisal and jute epoxy composite. Advances in Polymer Science and Technology: An International Journal 5(4): 51-54.

11. Avinash Kumar, Manoj Kumar Gupta, Srivastava RK, Harinder Singh (2014) Mechanical properties of hybrid polymer composite using banana/sisal fibre. Int J Eng Res Manage Technol 1: 44-50.

12. Himanshu Bisaria, Gupta MK, Shandilya P, Srivastava RK (2015) Effect of fibre length on mechanical properties of randomly oriented short jute fibre reinforced epoxy composite. Mater Today: Proceed 2: 11931199.

13. Avinash Kumar, Gupta MK, Srivastava RK (2014) Viscoelastic properties and Fracture Toughness of Hybrid Polymer Composite using Banana/ Sisal Fibre. I J Adv Res Sci Eng 3(7): 1-9.

14. Tanveer Alam, Gupta MK, Srivastava RK, Harinder Singh (2014) Thermal characterization and Fracture Toughness of sisal fibre reinforced polymer composite. I J Scienti Eng Technol 3(8): 1071-1073.

15. Gupta MK, Srivastava RK (2014) Tensile and flexural properties of sisal fibre reinforced epoxy composite: A comparison between unidirectional and mat form of fibres. Proced Mater Sci 5: 2434-2439.

16. Gupta MK, Srivastava RK (2015) Effect of sisal fibre loading on dynamic mechanical analysis and water absorption behaviour of jute fibre epoxy composite. Mater Today: Proceed 2(4-5): 2909-2917. 
17. Hariom Mourya, Gupta MK, Srivastava RK, Singh H (2015) Study on the mechanical properties of epoxy composite using short sisal fibre. Mater Today: Proceed 2(4-5): 1347-1355.

18. Saba N, Jawaid M, Othman, Alothman Y, Paridah MT (2016) A review on dynamic mechanical properties of natural fibre reinforced polymer composites. Const Build Mater 106: 149-159.

19. Gupta MK (2017) Effect of frequencies on dynamic mechanical properties of hybrid jute/sisal fibre reinforced epoxy composite. Adv Mater Process Technol 3(4): 651-664.

20. Sunil Singh Rana, Gupta MK, Srivastava RK (2017) Effect of variation in frequencies on dynamic mechanical properties of short sisal fibre reinforced epoxy composite. Materials Today: Proceed 4(2Part A): 3387-3396.

21. Pothan LA, Oommen (2003) Dynamic mechanical analysis of banana fibre reinforced polyester composites. Compos Sci Technol 63: 283293

22. Nair KCM, Thomas S, Groeninckx G (2001) Thermal and dynamic mechanical analysis of polysterine composites reinforced with short sisal fibre. Compos Sci Technol 61: 2519-2529.

23. Gupta MK, Srivastava RK (2017) Mechanical, thermal and dynamic mechanical analysis of jute fibre reinforced epoxy composite. Indian Fib Text Res 42: 64-71.

24. Gupta MK, Srivastava RK (2016) Properties of sisal fibre reinforced epoxy composite. Indian J Fib Text Res 41: 235-241.

25. Mohanty S, Verma SK, Nayak SK (2006) Dynamic mechanical and thermal properties of MAPE treated jute/HDPE composites. Compos Sci Technol 66: 538-547.

26. Shinoj S, Visvanathan RS, Panigrahi S, Varadharaju N (2011) Dynamic mechanical properties of Oil Palm Fibre (OPF) - linear low density polyethylene (LLDPE) biocomposites and study of fibre-matrix interactions. Biosys Eng 109(2): 99-107.

27. Gupta MK, Srivastava RK (2016) Tribological and dynamic mechanical analysis of epoxy based hybrid sisal/jute composite. Indian J Eng Mater Sci 23(1): 37-44.

28. Idicula M, Malhotra SK, Josheph K, Thomas S (2005) Dynamic mechanical analysis of randomly oriented intimately mixed short banana/sisal fibre reinforced polyester composites. Compos Sc Technol 65(7-8): 1077-1087.

29. Gupta MK, Vipul Deep (2017) Effect of stacking sequence on flexural and dynamic mechanical properties of hybrid sisal/glass polyester composite. American J Polym Sci Eng 5(1): 53-62.
30. Ornaghi HL, Bolner AS, Fiorio R, Zattera AJ, Amico SC (2010) Mechanical and dynamic mechanical analysis of hybrid composites molded by resin transfer molding. J Appl Polym Sci 118(2): 887-896.

31. Jarukumjorn K, Suppakarn N (2009) Effect of glass fiber hybridization on properties of sisal fiber-polypropylene composites. Compos Part B Eng 40(7): 623-627.

32. Romanzini D, Ornaghi HL, Amico SCZA (2012) Influence of fiber hybridization on the dynamic mechanical properties of glass/ramie fiber-reinforced polyester composites. J Reinf Plast Compos 31(23): 1652-1661.

33. Nayak SK, Mohanty S, Samal SK (2009) Influence of short bamboo/glass fiber on the thermal, dynamic mechanical and rheological properties of polypropylene hybrid composites. Mater Sci Eng A 523: 32-38.

34. Almeida JHS, Amico SC, Botelho EC, Amado FDR (2013) Hybridization effect on the mechanical properties of curaua/glass fiber composites. Compos Part B Eng 55: 492-497.

35. Ornaghi HL, da Silva HSP, Zattera AJ, Amico SC (2011) Hybridization effect on the mechanical and dynamic mechanical properties of curaua composites. Mater Sci Eng A 528: 7285-7289.

36. Samal SK, Mohanty S, Nayak SK (2009) Banana/glass fiber-reinforced polypropylene hybrid composites: fabrication and performance evaluation. Polym Plast Technol Eng 48(4): 397-414.

37. Devi LU, Bhagawan SS, Thomas S (2009) Dynamic mechanical analysis of pineapple leaf/glass hybrid fiber reinforced polyester composites. Polym Compos 31(6): 956-965.

38. Sreekala MS, Thomas S, Groeninckx G (2005) Dynamic mechanical properties of oil palm fiber/phenol formaldehyde and oil palm fiber/ glass hybrid phenol formaldehyde composites. Polym Compos 26(3): 388-400.

39. Shanmugam D, Thiruchitrambalam M (2013) Static and dynamic mechanical properties of alkali treated unidirectional continuous palmyra palm leaf stalk fibre/jute fibre reinforced hybrid polyester composites. Mater Des 97: 533-542.

40. Gupta MK, Gond RK (2017) Influence of concentrations of alkal treatment on mechanical and dynamic mechanical properties of hemp/ polyester composite. American J Polym Sci Eng 5(1): 24-33.

41. Ray D, Sarkar BK, Das S, Rana AK (2002) Dynamic mechanical and thermal analysis of vinylester-resin-matrix composites reinforced with untreated and alkali treated jute fibres. Compos Sci Technol 62: 911917.

Your next submission with Juniper Publishers will reach you the below assets

- Quality Editorial service

- Swift Peer Review

- Reprints availability

- E-prints Service

- Manuscript Podcast for convenient understanding

- Global attainment for your research

- Manuscript accessibility in different formats ( Pdf, E-pub, Full Text, Audio)

- Unceasing customer service

Track the below URL for one-step submission https://juniperpublishers.com/online-submission.php 